\title{
Formar professores de Matemática no Estado do Maranhão, Brasil: aspectos historiográficos ${ }^{*}$
}

\section{Math teachers formation in Maranhão State, Brazil: some remarks on historiography}

\section{Déa Nunes Fernandes}

Doutora em Educação Matemática pela Unesp e professora do Departamento de Matemática do Instituto Federal de Educação, Ciência e Tecnologia do Maranhão (IFMA) deanf13@hotmail.com

\section{Antonio Vicente Marafioti Garnica}

Doutor em Educação Matemática, professor da Unesp (Bauru e Rio Claro) e coordenador do Grupo de Pesquisa História Oral e Educação Matemática (GHOEM)

vgarnica@fc.unesp.br

Resumo:

O texto apresenta aspectos historiográficos relativos à formação de professores de Matemática em cursos superiores do estado do Maranhão, num período que tem como marco inicial a implantaçáo, na década de 1960, da primeira Licenciatura Plena em Matemática no estado. Seguindo os parâmetros da História Oral, foram entrevistados professores de três instituiçóes públicas de ensino superior do estado que trabalharam como docentes quando da implantação e/ou da elaboração dos projetos dos primeiros cursos de Licenciatura Plena em Matemática e alunos da primeira turma neles graduada.

Palavras-chave: Formação de Professores de Matemática; Estado do Maranhão; História Oral

\section{Abstract:}

This paper intends to sketch some historical remarks on the formation of math teachers in undergraduate courses in Maranhão State, Brazil, since the 60 's, the decade in which the first of these courses was created. Its methodological approach is given by Oral History and, in order to collect data, some professors and students were interviewed. Such teachers are those responsible for the projects - and its implementation - of the first three undergraduate courses in Maranháo, and the students are part of the first team formed by them in those institutions.

Keywords: Math Teachers Formation; Maranhão State, Brazil. Oral History

* Trabalho apresentado no GT Memória, História Oral e Trajetórias Biográficas 


\section{Artigos \& Ensaios}

1 - Com esse projeto, o Grupo visa a constituir um mapa das práticas de formação e atuação de professores de Matemática no Brasil. Algumas outras pesquisas vinculadas a esse projeto já foram desenvolvidase encontram-se disponíveis no site do GHOEM: Www. ghoem.com. ste texto apresenta um recorte da pesquisa de doutorado intitulada "Sobre - a formação do professor de Matemática no Maranhão: cartas para uma cartografia possível”, desenvolvida junto ao Programa de Pós-graduação em Educação Matemática da Universidade Estadual Paulista (Unesp) campus Rio Claro, cujo objetivo é configurar um registro histórico sobre o processo de formação de professores de Matemática no estado do Maranhão. Essa investigação vincula-se a uma das frentes de investigação (Formação de Professores, do Grupo de Pesquisa História Oral e Educação Matemática) do GHOEM [1], e teve como marco inicial a implantação, na década de 1960, do primeiro curso de Licenciatura Plena em Matemática naquele estado. A História Oral nos forneceu a base metodológica que nos permitiu criar fontes a partir da oralidade, concebendo as narrativas orais fixadas pela escrita como documentos históricos intencionalmente constituídos.

As narrativas são expressóes de memórias, portadoras de saberes localizados historicamente. Os lugares trazidos pelas memórias são referências de experiências vividas no passado e ressignificadas no presente das narrativas. Num trabalho que se vale da História Oral, as narrativas das experiências vividas - carregadas de saberes da experiência - transformam-se em objeto de investigação, possibilitando-nos compreender, à luz das preocupaçóes do tempo presente, os sentidos do que foi vivido, do que foi experienciado. A experiência e o saber da experiência são por nós entendidos no sentido dado por Jorge Larossa:

A experiência é aquilo que nos passa, que nos acontece, que nos toca, e ao nos tocar, nos forma ou nos transforma, nos constitui, nos faz como somos, marca nossa maneira de ser, configura nossa pessoa e nossa personalidade...

O saber da experiência: o que se adquire no modo como alguém vai respondendo ao que vai lhe acontecendo ao longo da vida e ao modo como vamos dando sentido ao acontecer do que nos acontece... (LARROSA, 2002: 21-27)

Larrosa ainda destaca que o saber da experiência se dá na relação entre o conhecimento e a vida humana. A experiência é uma espécie de mediação entre ambos. Diferentemente do conhecimento científico, o saber da experiência não está fora de nós, mas só tem sentido no modo como configura uma personalidade, um caráter, uma sensibilidade ou, em definitivo, uma forma humana singular de estar no mundo. E assim sendo, o saber da experiência não pode beneficiar-se de qualquer alforria, ou seja, "ninguém pode apreender da experiência de outro, a menos que essa experiência seja de algum modo revivida e tornada própria” (LARROSA, 2002: 27). Desse modo, quando tomamos as narrativas das experiências vividas como fontes de investigação, o que analisamos não é, propriamente, a experiência do outro, mas o relato dessa experiência. Essa parece ser uma distinção óbvia, mas deve ser reafirmada: eu só me aproximo da experiência a partir de mediaçôes. A narrativa da experiência vivida é uma dessas formas de aproximaçáo. Assim, o que eu capto não é a experiência do outro, mas aspectos dessa experiência a partir do que o outro me relata do que viveu. Essa parece ser a única forma possível de tornar própria a experiência do outro, e é segundo essa perspectiva que a História Oral, notadamente, atua.

Em síntese, a pesquisa tem em seu âmago uma questão propriamente 
historiográfica [2], e a partir dessa questão o exercício de (re)constituição de uma versão histórica sobre o cenário da formação de professores de Matemática no Maranhão é elaborado, tendo como fundante o diálogo com fontes tanto orais (criadas) quanto escritas (já disponíveis em acervos, como documentos oficiais, projetos pedagógicos de cursos, relatos de entrevistas realizadas por outros autores). As fontes orais foram constituídas a partir de entrevistas com dezesseis profissionais da educação envolvidos no processo de implantação dos primeiros projetos de formação de professores de Matemática em três instituições públicas de ensino superior desse Estado - a Universidade Federal do Maranhão, a Universidade Estadual do Maranhão e o então Centro Federal de Educação, Ciência e Tecnologia do Maranhão. Foram nossos colaboradores: Raimundo Renato Patrício, Maria Eufrásia Campos, José de Ribamar Rodrigues Siqueira, Jocelino Ribeiro Melo, Leila Ribeiro Veiga, Vera Lúcia Lobato Almeida, Francisco Pinto Lima, Joaquim Teixeira Lopes, Raimundo Merval Morais Gonçalves, José Gilson Sales e Silva, José Eduardo Gonçalves de Jesus, Alexandre Pereira Sousa, Eliane Maria Pinto Pedrosa, Maria Cristina Moreira da Silva, Marise Piedade de Carvalho e Dalva Rocha Pereira.

Nossa intenção aqui é apresentar nossa compreensão acerca de alguns aspectos historiográficos referentes ao cenário da formação de professores de Matemática no Maranhão quando da implantação do primeiro projeto de formação de professores de Matemática na atual Universidade Federal do Maranhão.

\section{UM CENÁRIO E AS COMPREENSÓES POSSÍVEIS}

A partir da perspectiva metodológica ora assumida, na interlocução com as fontes mobilizadas na pesquisa e com autores de outros campos do conhecimento, foi possível compreender a nítida situação periférica em que se encontrava a educação maranhense em relação a alguns estados brasileiros, no momento político em que se deu a implantação do primeiro projeto de formação de Matemática na atual Universidade Federal, no ano de 1969. Enquanto no final da década de 1960 muitos estados brasileiros organizavam-se para a expansáo do ensino superior - referenciada pela Reforma Universitária (Lei no 5.540/68) -, o estado do Maranhão empenhava-se no processo de implantação de sua primeira universidade pública, a atual Universidade Federal. Esta começou a configurar-se com criação da Fundação Universidade do Maranhão - FUM, em 1966. Até então, respondiam pela educação superior maranhense as Faculdades Isoladas, dentre estas a Faculdade de Direito de São Luís e a Faculdade de Farmácia e Odontologia de São Luís - ambas federais -, a Faculdade de Ciências Econômicas e aquelas que integravam a Universidade (Católica) do Maranhão: Faculdade de Ciências Médicas do Maranhão, a Faculdade de Filosofia, Ciências e Letras do Maranhão, a Escola de Enfermagem São Francisco de Assis, das Irmãs Terceiras, a Faculdade de Serviço Social do Maranhão, das Irmãs Missionárias de Jesus Crucificado. Com a criação da FUM, progressivamente foi sendo instituída à época a Universidade do Maranhão - atual Universidade Federal do Maranhão - que passa a agregar todas essas citadas faculdades (MEIRELES, 1994: 79-80)

Percebe-se que embora fosse visível a carência de professores habilitados na área de Matemática no Maranhão não existia nenhuma instituição ensino superior que respondesse pela formação docente nessa área no Estado. Os professores que atuavam nessa área, em geral, eram formados nas Faculdades Isoladas ou engenheiros graduados fora do Estado, ou mesmo alunos que, por se desta-
2 - Entendemos que a História Oral - concebida como metodologia de pesquisa-serve a investigações dos mais diversos matizes e não apenas às investigações de caráter historiográfico. Sempre há, porém, nos projetos com História Oral, uma face memorialística explícita (sejam ou não os projetos propriamente historiográficos), o que diferencia essa abordagem de outras modalidades de pesquisa qualitativa que também usam entrevistas como forma privilegiada de coleta de dados. 
carem durante o curso secundário, ao concluí-lo eram convidados para trabalhar com contratos temporários, renováveis a cada ano. Foi o que aconteceu com um de nossos entrevistados, o professor Jocelino Ribeiro, que ingressou na carreira do magistério como professor do ensino secundário, na então Escola Técnica Federal do Maranhão, a convite do então diretor-geral, o professor Ronald Carvalho, após ter concluído o Curso Científico nesta instituição. A formalização para atuar na docência era de responsabilidade da Campanha de Aperfeiçoamento e Difusão do Ensino Secundário - CADES. Tratava-se de uma ação governamental emergencial implantada pelo governo federal (Decreto no 34.638, de 17 de novembro de 1953) para enfrentar a escassez de professores habilitados no país para atuar no ensino secundário. Dentre outras funçóes, cabia à CADES, por meio de um modelo de formação que passava pela preparação didática e de conteúdos específicos, a realização de cursos intensivos, com vistas aos Exames de Suficiência para o exercício do magistério. $\mathrm{O}$ profissional que tinha interesse em ensinar na área de Matemática no ensino secundário, por exemplo, mas que não tinha habilitação nessa área, participava dos cursos intensivos oferecidos pela CADES e, após submissáo e aprovaçáo no Exame de Suficiência recebia um registro que o autorizava a ensinar (BARALDI e GARNICA, 2005).

A partir da década de 1960 os ideais modernizantes contaminaram tanto a política como a economia da época e reproduziram-se no campo da educaçáo maranhense sob vários aspectos. Medidas governamentais emergenciais voltadas para a expansão do ensino no Estado foram implantadas na tentativa de enfrentar a precária situação em que a educação maranhense se encontrava: "no estado do Maranhão - com cento e vinte e oito municípios - havia apenas dois ginásios estaduais: $\mathrm{o}$ Liceu Maranhense e a Escola Normal - os dois na capital e funcionando no mesmo prédio", palavras do professor José Maria Cabral Marques (FARIA e MONTENEGRO, 2005, p. 222-3). Dentre essas medidas destacava-se a implantação da Televisão Educativa do Maranhão (TVE-MA), com sede em São Luís. Essa televisão passou a responder pelo ensino regular oficial das séries ginasiais, tanto na capital do estado como em alguns povoados do interior, atingindo um público de aproximadamente treze mil alunos (BOMENY, 1981; BONFIM, 1985). Quatro de nossas entrevistadas revelam uma relação próxima a esse projeto: Eliane Pedrosa e Marise Carvalho cursaram o ginásio numa das Bases de Recepção da TVE- MA, enquanto que Leila Ribeiro e Vera Almeida foram orientadoras educacionais em salas de aulas. Dois outros projetos educacionais foram implantados no intuito de atingir os interiores maranhenses: o Projeto Bandeirante - que intencionava suprir a carência de ginásios, em municípios maranhenses (BONFIM, 1985; KREUTZ, 1983), e o Projeto João-de-Barro, que objetivava inserir o homem rural no processo de desenvolvimento sócio-econômico racionalizado (KREUTZ, 1983). Dalva Rocha, uma de nossas entrevistadas, trabalhou nesse projeto.

Essas medidas, ao mesmo tempo em que proporcionaram a expansão do ensino maranhense, tornaram mais urgente a necessidade de formar professores no Estado, principalmente na área de Matemática. Com a Lei no 5.692/71 chegou o tempo da exigência de que o exercício do magistério no ensino de $1^{\circ}$ e $2^{\circ}$ graus fosse desempenhado por graduados em cursos de Licenciatura plena, o que potencializou a urgência de implantaçáo de cursos de licenciatura plena em Matemática no Estado: "urgia pressa na implantação do curso de graduação de Licenciatura em Matemática; a CADES não estava mais satisfazendo...” ressalta a professora entrevistada Vera Almeida. 
Oficialmente, o primeiro curso de Licenciatura Plena em Matemática no Maranhão foi instituído na Universidade do Maranhão (a atual Universidade Federal), junto à Faculdade de Filosofia, Ciência e Letras (Resoluçáo no 79, de 04 de janeiro de 1969). Contudo, na prática, o currículo desse curso só veio a ter um desenho próprio, mais nítido, depois que a primeira turma do curso de Matemática bacharelado se formou no ano de 1972.

O curso de Matemática foi criado oficialmente pela Universidade Federal, mas, dada a carência de profissionais no Estado com formação na área, foi necessário o recrutamento de professores de outros estados para compor o quadro de professores do curso. Nesse cenário percebe-se a marcante presença de profissionais com formação matemática oriunda do estado do Ceará. Os quatro primeiros professores - os colonizadores, no sentido original do termo, o de tomar conta de uma seara inóspita - do curso de Matemática da Universidade do Maranhão foram bacharéis formados pela Universidade Federal do Ceará, instituição cujos cursos de graduação e pós-graduação em Matemática, na época, eram referência na região. Inicialmente vieram do Ceará para trabalhar na Universidade do Maranhão, a convite do então reitor Cônego Ribamar Carvalho, os professores Gualter Gonçalves, Raimundo Renato Patrício, Maria Eufrásia Campos, em seguida juntou-se a esse grupo o professor José de Ribamar Rodrigues Siqueira.

Outro aspecto a ser ressaltado nesse cenário refere-se à atuação da Superintendência de Desenvolvimento do Nordeste - Sudene (Lei no 3.962, de 15 de dezembro de 1959) - na formação de profissionais para atuar na área de Matemática. A formação acadêmica em nível superior de três desses professores colonizadores - Raimundo Renato Patrício, Maria Eufrásia Campos e José de Ribamar Rodrigues Siqueira - ocorreu com o apoio da Sudene, por meio de sua política de concessáo de bolsas de estudos para alunos carentes da regiáo Nordeste com o intuito de formar profissionais em áreas vistas como essenciais ao desenvolvimento regiáo, dentre elas a Matemática. A Sudene configurou-se, assim, como um elemento significativo na formação de professores de Matemática, na região Nordeste, em particular no Maranhão.

A narrativa dos professores entrevistados envolvidos no desenvolvimento das atividades do primeiro projeto de formação de professores de Matemática da atual Universidade Federal aponta para a inexistência de um planejamento prévio, por parte da universidade, na implantaçáo do curso de Matemática, o que veio a requerer dos colonizadores a busca por estratégias de sobrevivência diante do caos que a urgência e a carência lhes impediam. Tais carências manifestavam na falta de professores, na ausência de dependências físicas adequadas, bem como de uma biblioteca com acervo mínimo voltado para a área das Ciências Exatas. Dentre tais estratégias destacam: produzir, eles mesmos, apostilas para os alunos; dividir o espaço da sala de aula com outros professores, atendendo duas ou mais turmas ao mesmo tempo; e convocar alunos da primeira turma do curso de Matemática para ministrar aulas em turmas de períodos iniciais. Neste sentido, as atividades do curso foram sendo desenvolvidas à base de muita improvisação.

No que tange ao modelo de formação, percebe-se que o projeto de formaçáo de professores de Matemática da Universidade Federal, no primeiro momento, foi caracterizado por uma concentração na formação Matemática, seguida por uma complementaçáo pedagógica (modelo de formaçáo resultante do Decreto-lei no 1.190 , de 04 de abril de 1939, que se estendeu para todo o país, compondo o modelo que ficou conhecido como esquema $3+1$ ). A Universidade Federal iniciou as atividades do curso de Licenciatura Plena em Matemática sem ter uma proposta de currículo definida. Embora existisse, naquele momento, uma reconhecida carência de professores com 
formação Matemática para atuar no ensino de $2^{\circ}$ grau no Maranhão, não se percebe essa formação como preocupação primeira da Universidade: parece ter havido uma preocupação maior, à época, com a formação do quadro docente do Departamento de Matemática da Universidade, ficando, assim, a formação de professores de Matemática em segundo plano.

O modelo gerenciador da formação desse primeiro curso de Licenciatura Plena em Matemática no Estado, portanto, pautou-se inicialmente mais pela formação de matemáticos do que, propriamente, pela crença na necessidade de formar, mais profunda e adequadamente, o professor que atuaria na educaçáo de crianças e adolescentes. Nesse quadro, confundiram-se formar em Matemática, formar para a Matemática e formar professores que ensinarão Matemática.

Com a implantação do curso de Licenciatura Plena em Matemática na Universidade Federal, a cidade de São Luís tornou-se o centro da formação de professores de Matemática no Estado, cenário que só começou a se alterar, ainda que de maneira tímida, na década de 1980, quando a Universidade Estadual foi incluída no cenário da formação de professores de Matemática com a criação do Curso de Ciências (com habilitação em Matemática), em dois municípios maranhenses, Imperatriz e Caxias. Somente na década de 1990 foi possível perceber, de modo mais nítido, uma descentralização dessa formação, quando as três instituições públicas de ensino superior do Estado adotaram uma política de expansão aligeirada do ensino superior, que, em curto prazo, atingiu um número significativo de municípios maranhenses.

\section{REFERÊNCIAS BIBLIOGRÁFICAS}

BARALDI, I. M. e GARNICA, A.V.M. "Traços de uma paisagem: os anos 60 e 1970 e a formação de professores de matemática na regiáo de Bauru (SP)". Revista de Educação, PUC-Campinas. Campinas, n.18, p.65-74, jun.2005.

BOMENY, H. M. B. Paraíso Tropical: A Ideologia do Civismo na TVE do Maranhão. Rio de Janeiro: Achiamé, 1981.

BONFIM, M. N. B. Do Velho ao Novo: Política e Educação no Maranhão. São Luís: Edufma/Secret. Educ., 1985.

BRASIL. Presidência da República. Lei no 3.962, de 15 de dezembro de 1959. Cria a Superintendência de Desenvolvimento do Nordeste. Sudene. Recife, 1959.

. Ministério da Educação e Cultura. Lei no 5.692, de 11 de agosto de 1971.

Fixa Diretrizes e Bases para o Ensino de $1^{\circ}$ e $2^{\circ}$ graus. Brasília, 1971.

FARIA, R. H. M. e MONTENEGRO, A. Memórias de Professores: Histórias da UFMA e Outras Histórias. São Luís: Universidade Federal do Maranhão/ Departamento de História, Brasília, 2005.

FERNANDES, D.N. "Sobre a formação do professor de matemática no Maranhão: cartas para uma cartografia possível”. Rio Claro, 2011. 389 f. Tese (Doutorado em Educação Matemática) - Instituto de Geociências e Ciências Exatas, Universidade Estadual Paulista, Rio Claro, 2011.

FUNDAÇÃO UNIVERSIDADE DO MARANHÃO. Conselho Diretor. Resolução $\mathrm{n}^{\circ}$ 79, de 04 de janeiro de 1969. Cria cursos na Universidade do Maranhão. São Luís, 1969.

KREUTZ, A. O Projeto "João de Barro" e o Poder Político no Maranhão. São Luís: UFMA, 1983.

LARROSA, J. "Notas sobre a experiência e o saber de experiência”. Revista Brasileira de Educação. Rio de Janeiro, n. 19, p. 20-28, jan/fev/mar/abr, 2002.

MEIRELES, M. M. Dez Estudos Históricos. São Luís: Alumar, 1994. 